\title{
Kinematics and load-sharing of an anterior thoracolumbar spinal reconstruction construct with PEEK rods: an in vitro biomechanical
}

study

Ruozhou Zhou, MD ${ }^{\mathrm{a}, \mathrm{b}}$, Zhiping Huang, $\mathrm{MD}^{\mathrm{a}}$,Xiang Liu, MD ${ }^{\mathrm{a}}$, Jie Tong $\mathrm{MD}^{\mathrm{b}}$, Wei Ji, MD ${ }^{\mathrm{a}}$, Sheting Liu, MD ${ }^{\mathrm{b}}$, Qingan Zhu, $\mathrm{PhD}^{\mathrm{a} *}$

${ }^{\text {a }}$ Department of Spine Surgery, Nanfang Hospital, Southern Medical University, Guangzhou, Guangdong, People's Republic of China

${ }^{\mathrm{b}}$ Department of Spine Surgery, the First People's Hospital of Chenzhou, Chenzhou, Hunan, People's Republic of China

${ }^{*}$ Corresponding author

Qingan $\mathrm{Zhu}, \mathrm{PhD}$

Department of Spinal Surgery, Nanfang Hospital, 1838 N. Guangzhou Ave, Guangzhou 510515, People's Republic of China

Tel: +86-20-61641724

Fax: +86-20-61641724

E-mail: qinganzhu@gmail.com

We are grateful for the financial support from National Science Foundation of China (81171765). No benefits in any form have been or will be received from a commercial party related directly or indirectly to the subject of this manuscript.

Conflicts of Interest: None of the authors has financial or other conflicts of interest concerning this study. 
Words of the abstract: 276

Background: Polyetheretherketone rod constructs provide adequate spinal stability. Kinematics and load sharing of anterior thoracolumbar reconstruction with polyetheretherketone rods under preload remains unknown.

Methods: Eight human cadaveric specimens (T11-L3) were subjected to a pure moment of $5.0 \mathrm{Nm}$ in flexion-extension, lateral bending and axial rotation, and flexion-extension with a compressive preload of $300 \mathrm{~N}$. An anterior reconstruction of L1 corpectomy was conducted with a surrogate bone graft and anterior rod constructs (polyetheretherketone or titanium rods). An axial load-cell was built in the surrogate bone graft to measure the compressive force in the graft. Range of motion, neutral zone and compressive force in the graft were compared between constructs.

Findings: The polyetheretherketone rod construct resulted in more motion than the titanium rod construct, particularly in extension $(\mathrm{P}=0.011)$ and axial rotation $(\mathrm{P}=0.001)$, but less motion than the intact in all directions except in axial rotation. There was no difference in range of motion or neutral zone between constructs in flexion-extension under preload. The polyetheretherketone rod construct kept the graft compressed $52 \mathrm{~N}$ which was similar to the titanium rod construct $(63 \mathrm{~N})$, but allowed the graft compressed more under the preload $(203 \mathrm{~N}$ vs. $123 \mathrm{~N}, \mathrm{P}=0.003)$. The compressive forces fluctuated in flexion-extension without preload, but increased in flexion and decreased in extension under preload.

Interpretation: The polyetheretherketone rod construct allowed more motion compared to the titanium rod construct, but provided stability in flexion and lateral bending without preload, and flexion and extension under preload. The anterior graft shared higher load under preload, particularly for the polyetheretherketone rod construct. The results of this study suggest that rigidity of rods in the anterior reconstruction affects kinematic behavior and load sharing.

Key words: polyetheretherketone rod, kinematics, load sharing, corpectomy, anterior reconstruction 
Words of the text: 2940

\section{Introduction}

All kind of spinal implants provide initial stability until the bone fusion is achieved. Sufficient rigidity of the implants is of utmost importance for a higher fusion rate (Feighan JE, 1995). However, stiffness of metallic implants may exceed the stiffness for a successful fusion and reduce the load sharing in the graft, causing bone-screw interface loosening, intervertebral cage subsidence, delayed fusion or implants failure (Brodke DS, 2006; Reidy D , 2004; Yu AK, 2015).

Polyetheretherketone (PEEK), as a kind of non-metallic material, is used to lessen the adverse effects of rigid instrumentation (Kurtz SM, 2007). PEEK is regarded as a promising alternative to titanium alloy for its special material features. There are attractive advantages of PEEK, such as biocompatible to the spinal cord (Rivard $\mathrm{CH}$, 2002) and radiolucent for evaluation of bony fusion (Ferguson SJ, 2006). PEEK was initially used as intervertebral cages in the cervical and lumbar spine, then rods in posterior and anterior screw-rod fixations of lumbar spine (De Iure F, 2012; Qi L, 2013; Ormond DR, 2015), and is often considered as a semi-rigid fixation which reduces stress shielding (Turner JL, 2010; Abode-Iyamah K, 2014).

Previous studies addressed the biomechanical effect of PEEK rods in posterior and anterior screw-rod fixations (Sengupta DK, 2013; Moon SM, 2009; Ponnappan RK, 2009; Gornet MF, 2011), as well as anterior fusion cages (Moon SM, 2009; Voronov LI, 2014; Chang UK, 2006). Posterior PEEK rod constructs provided comparable stabilization as the rigid posterior fixation and slightly higher load sharing (Turner JL, 2010; Sengupta DK, 2013). An all-PEEK anterior construct may provide adequate stability in the coronal and sagittal planes but compromise the stability significantly in axial rotation (Moon SM, 2009). In addition, load sharing of different anterior thoracolumbar instrumentations was compared on plastic vertebral surrogates (Brodke DS, 2003). In addition, compressive follower preload simulates physiological loading profiles and is used for evaluation of kinematics and load sharing (Patwardhan AG, 1999; Niosi CA, 2006; Zhu QA, 2012). However, few studies measured load sharing of anterior bone graft in an in vitro cadaveric model (Chang 
UK, 2006).

In the present study, an in vitro biomechanical evaluation was designed to meet important data with respect to the PEEK rod constructs in anterior thoracolumbar reconstruction. The purpose of this investigation was to evaluate kinematics of anterior reconstruction constructs with PEEK and titanium rods, and compare load sharing between the constructs in flexion and extension under preload.

\section{Methods}

\subsection{Specimen preparation}

Eight fresh frozen cadaveric thoracolumbar spines (T11-L3) were tested. Anteroposterior and lateral radiographs of the specimens were taken to ensure the absence of fractures, deformities, and metastatic disease. The bone mineral density was also quantified using dual-energy x-ray absorptiometry to ensure the exclusion of osteoporotic specimens ( $\mathrm{T}$ score $<-2.5$ ). The donors were all male, and the age ranged from 35 to 70 years with average age of 44.3 years. Before the test, each specimen was thawed overnight at room temperature and prepared by dissecting the musculature, while preserving all ligaments, joint capsules and discs. The T11 and L3 were potted in dental stone mounts such that the L1 superior endplate remained horizontal.

\subsection{Biomechanical Testing}

Three-dimensional flexibility tests were conducted on each specimen under three different conditions: intact, anterior reconstruction of L1 corpectomy with PEEK rod construct, and anterior reconstruction of L1 corpectomy with titanium rod construct. The last two conditions were tested with a random sequence.

Biomechanical testing was conducted on the custom-designed spine testing machine (Figure 1) (Dvorak MF, 2003). The L3 was secured to the table of the testing machine. The T11 was connected to the loading arm driven by a servo-motor that applied a pure moment to the specimen through an articulated arm, while the specimen was allowed to move in an unconstrained three-dimensional fashion (Niosi CA, 2006; Zhu QA, 2007). The pure moment was monitored by a torque transducer 
(YR-403-30NM, Yom Electronic Technology, Guangzhou, China) amounted in the distal arm. A pure moment of 5.0 Nm was applied in flexion-extension, left and right lateral bending, and left and right axial rotation at a rate of $1 \%$, and additionally in flexion-extension with a compressive preload of $300 \mathrm{~N}$. The pure moment was applied for three completely reversed loading cycles. Specimens were kept moist with saline throughout the test to prevent the dehydration of the soft tissues (Wilke HJ, 1998).

The compressive preload was applied though a system of ropes and pulleys and dead weight of $300 \mathrm{~N}$ (Figure 1). The purpose of a preload was to simulate physiologic compressive in an in vitro spine study (Niosi CA, 2006; Zhu QA, 2007). The ropes were attached to the T11 dental stone mount and passed eyelets on the L3 mount. The path of the preload was optimized in the neutral position so that the compressive preload did not create an obvious motion in flexion or extension.

A custom-made surrogate bone graft consisted of a subminiature load cell (DY-1D-100KG, Yom Electronic Technology, Guangzhou, China) and two metal cylindrical cups (Figure 2). The capacity of the force transducer is $1000 \mathrm{~N}$ with accuracy of $0.5 \%$. The diameter of the graft was $22 \mathrm{~mm}$ and overall height of the graft was achieved with metal shims of $1 \mathrm{~mm}$ in thickness and different cylindrical cups (Figure 2). The surrogate graft was verified with dead weight before testing, and monitored the axial compressive force during implantation and flexibility test.

The L1 corpectomy was performed from the right side. The partial body of L1 and adjacent T12/L1 and L1/2 discs were removed in a standard fashion. The anterior and posterior longitudinal ligaments were carefully preserved. The surrogate bone graft with appropriate height was inserted in the corpectomy defect. Two titanium 6.5-mm bi-cortical screws were inserted laterally into the body of T12 and L2 respectively, and connected by two 5.5-mm titanium or PEEK rods (Stable Surgical Implant Co. Ltd, Foshan, Guangdong, China) over T12 and L2 (Figure 2). The surrogate bone graft was compressed in accordance with clinical practice (Figure 3 ).

During flexibility test, the position of each vertebra was monitored using four rigidly attached marker carrier with 4 non-collinear infrared light-emitting diodes (LED)(Figure 1). A marker carrier with four LEDs on the base of the spine machine 
defined a general specimen coordinate system. An optoelectronic camera system (Optotrak Certus, Northern Digital, Waterloo, Canada) was used to measure the three-dimensional coordinates of the markers. Pure moment, compressive force in the graft and vertebral position were collected during the flexibility test at a sampling frequency of $20 \mathrm{~Hz}$. The data of the third loading cycle was used for the analysis.

The kinematics was compared for the different test conditions by looking at the intersegmental motion between T12 and L2. Specifically, range of motion (ROM) and neutral zone (NZ) along the primary axis of rotation were calculated. The ROM was defined as the measured difference between neutral position and the displacement at application of the maximal moment of $5.0 \mathrm{Nm}$ in the third loading cycle on the ROM-torque graph. The NZ was measured as the difference in the loading and unloading curves at zero Nm, as described previously (Dvorak MF, 2005). Furthermore, we monitored the compressive force in the graft in the neutral position, flexion and extension during flexibility test with and without preload (Figure 3)

\subsection{Statistical analysis}

All analyses were performed using Statistica 7.1 (StatSoft, Inc., Tulsa, OK) software program. The effects of rods and the preload on ROM and NZ were determined using repeated measures analysis of variance at a $95 \%$ level of significance. Student-Newman-Keuls post-hoc analysis was used to determine the differences between specific cases. The compressive forces in the graft were compared between two constructs using paired $t$-test with significant level at $p<0.05$.

\section{Results}

\subsection{Kinematics}

Compared with the intact spine, the titanium rod construct significantly reduced ROM in flexion, extension and lateral bending, while the PEEK rod construct significantly in flexion and lateral bending. However, both constructs allowed more motion in axial rotation (Figure 4). The PEEK rod construct resulted in greater ROM than the titanium rod construct, particularly in extension $(P=0.011)$ and axial rotation $(P=0.001)$. Under the preload, both constructs constrained the reconstruction in 
flexion and extension, and there was no difference in ROMs between two constructs (Figure 4). Note of that the preload significantly increased ROM of the intact specimen in extension under preload.

The titanium rod construct reduced NZ significantly in lateral bending $(P=0.001)$ and in flexion-extension with $\operatorname{preload}(P=0.031)$, while the PEEK rod construct reduced NZ compared to the intact (Table 1). The NZ following the two constructs was increased significantly in axial rotation when compared with the intact . In addition, the preload resulted in significantly greater NZ of intact specimen in flexion-extension than the intact specimen without preload $\left(0.8^{\circ}\right.$ vs. $\left.0.3^{\circ}\right)$.

\subsection{Load sharing}

The bone graft was compressed to $63 \mathrm{~N}$ and $52 \mathrm{~N}$ after installation with the titanium and PEEK rod constructs, respectively (Table 2). Although the compressive force in the graft increased averagely in flexion and extension, there was a considerable variation in force and thus lack of a clear pattern in flexion or extension without preload.

The preload increased compressive force in the graft to $123 \mathrm{~N}$ and $203 \mathrm{~N}$ with the titanium and PEEK rod constructs, respectively (Table 2). The compressive force in the graft presented a clear pattern in which the force decreased in extension and increased in flexion (Figure 3). The PEEK rod construct led to significantly greater compressive force in the graft than the titanium rod construct in neutral position $(\mathrm{P}=0.003)$, flexion $(\mathrm{P}=0.009)$ and extension $(\mathrm{P}=0.025)$, respectively (Table 2$)$. However, there was no significant difference in the loading changes in flexion or extension between two constructs (Figure 5).

\section{Discussion}

The purpose of this in vitro study was to perform a biomechanical analysis to determine if PEEK rod construct in anterior thoracolumbar reconstruction maintains spinal stability and increases load sharing in the bone graft. The PEEK rod construct allowed more motion compared to the titanium rod construct, but constrained the anterior reconstruction in flexion and lateral bending without preload, and in flexion 
and extension under preload. The anterior graft shared higher more compressive force under preload, particularly with the PEEK rod construct. The present study indicates that rigidity of rods in the anterior reconstruction affects kinematic behavior and load sharing.

The hypothesis that semi-rigid or dynamic instrumentation lead to higher load-sharing in the anterior column has been validated for the anterior and posterior thoracolumbar instrumentation (Sengupta DK, 2013; Chang UK, 2006; Brodke DS, 2003). Brodke et al (Brodke DS, 2003) compared six anterior thoracolumbar implants with plate and rod styles using plastic blocks as vertebral surrogates, and showed that load shared by the graft ranged from $63 \%$ to $89 \%$, and the design of the instrumentation system affected the biomechanical behavior regardless a plate or rod construct. Sengupta et al (Sengupta DK, 2013) evaluated posterior pedicle screw fixations with PEEK and titanium rods on plastic blocks, and showed the anterior column load-sharing 55\% with rigid rods and 59\% with PEEK rods, respectively. Ahn et al (Ahn Y, 2008) analyzed posterior pedicle screw-rod device using a finite element model, showed that the PEEK and titanium rod constructs sustained $29 \%$ and $67 \%$ of axial compressive force, respectively. Chang et al (Chang UK, 2006) evaluated kinematics and load sharing of the anterior reconstruction of T11 corpectomy with thicker and regular titanium rod constructs, and showed no difference in kinematics and load sharing between constructs. The anterior bone graft was attached strain gauges and calibrated before implantation, and was used to monitor the graft loading in all six motion directions under a preload of $300 \mathrm{~N}$. In his study, the compressive force in the graft was $224 \mathrm{~N}$, and higher than $123 \mathrm{~N}$ in the present study. Other interesting finding was that the graft loading decreased in all directions except in lateral bending contralateral to the approach side. However, the present study showed the compressive force in the graft increased in flexion. The discrepancy between studies may associate with levels of corpectomy, preload techniques and the anterior reconstruction procedures. The current study clearly demonstrated that the PEEK rod construct allowed higher compressive force to the anterior column than the titanium rod construct under preload. This observation is consistent in general with literatures, 
where a semi-rigid and dynamic rod is an important factor to the load sharing of the anterior column. As a result, the growth and reconstruction of bone graft can be improved, as well as the quality of fusion, the bone-screw interface integrity and the implant durability (Kokkinos PA, 2009; Patel MJ, 2009).

In light of the biomechanical concerns relating to the surrogate bone graft embedded with a load cell, difference in stiffness between the graft used in this study and titanium cages used in clinic may exaggerate the load sharing to some extent. Technically, it is difficult to measure the graft loading directly without modification to the graft, particularly for an in vitro test. The graft loading is evaluated with implantation of rigid, semi-rigid and dynamic devices using plastic vertebral surrogates (Sengupta DK, 2013; Brodke DS, 2003; Ahn Y, 2008; Brodke DS, 2001), but effects of the graft stiffness on the loading sharing remain unknown. Indirect evidence showed no difference in range of motion between anterior reconstructions with the PEEK and titanium cages (Moon SM, 2009). In addition, Brodke et al (Brodke DS, 2003) identified that load sharing capabilities varied inversely to stiffness of the whole construct, i.e. range of motion of the whole construct. We expected that the custom-made bone graft in the present study didn't change the immediate kinematic behavior as it was implanted like a titanium cage. Therefore, the authors speculated with caution that the load sharing by the graft used in this study might be similar to the load sharing by titanium cage used in clinic.

The other aim of this study was to compare the kinematics of a thoracolumbar corpectomy reconstruction with PEEK rods to the titanium rods. The present results show that ROMs and NZs are greater with the PEEK rod construct than the titanium rod construct, particularly in flexion and axial rotation. Note of that the ROM difference in flexion between PEEK and titanium rods is lesser under preload, indicating that weight bearing and muscle protection enhance semi-rigid rod construct more than the rigid rod construct. Moon et al (Moon SM, 2009) assessed biomechanical differences between anterior reconstructions following L1corpectomy using PEEK and titanium rods, and found no difference in ROM between two constructs. Compared with Moon's results, the present study achieved higher 
stabilization with titanium rods in flexion ( $22 \%$ vs. $80 \%$ ), extension (54\% vs. $69 \%)$, lateral bending (20\% vs. $41 \%)$ and axial rotation (122\% vs. $138 \%)$. In addition, ROMs with PEEK rods in the present study seems less in flexion (54\% vs. 84\%) and lateral bending (37\% vs. $42 \%)$, but more in extension (81\% vs. 66\%) and axial rotation (311\% vs. $148 \%$ ). The present results were consistent with Moon's result in general, showing that the overall stability was weaker with PEEK rods than titanium rods. Conditions of specimens and surgical procedure may contribute to the discrepancy in kinematics between studies. In the present study, the thoracolumbar spine degeneration may be less as the age of the donors is in adult, rather than in senior. In addition, the present study is consistent to the previous study (Chang UK, 2006), where ROM with titanium rod construct decreased more in flexion and lateral bending, but less in extension and axial rotation.

The strength of the present study was to evaluate load sharing and kinematics of anterior reconstruction with less rigid rods construct under preload. This protocol is critical for load sharing of implantation and loads in facet joints (Chang UK, 2006; Sjovold SG, 2012; Niosi CA, 2008), and popular in stabilization evaluation (Voronov LI, 2014; Niosi CA, 2006; Zhu QA, 2007; Zhu QA, 2012). The surrogate bone graft was used to show the load sharing of the anterior reconstruction. We demonstrated that the anterior graft sustained considerable compressive force under preload, particularly with PEEK rod construct.

The limitations of the present study must be acknowledged. In clinic, the size of bone graft changes with the defect following the corpectomy. However, we used one-size graft for all specimens to keep the same stiffness of the graft. Due to a small sample size, constructs with PEEK and titanium rods were tested repeatedly on the same specimen. The test sequence was randomized in order to reduce effect of any screw loosening or possible deteriorate of the specimen. Ideally, a six-axis load cell embedded into the graft allows identifying loads in detail, such as shear force and torsional moment in the graft. In addition, a large age range for the cadaveric specimens may affect the kinematics and load sharing of the graft. In the present study, the preload path was constraint only at the top and bottom vertebrae, and did 
not follow the spinal column contour. Subsequently, NZ in flexion-extension increased with the preload for the intact specimen. This finding was similar to our previous study (Niosi CA, 2006), but different to most of previous studies (Fry RW, 2014). We think the NZ sensitive to the set-up of follower load, and the friction between the cable and eyelet may contribute to the increase of NZ with preload.

In summary, the PEEK rod construct allowed more motion compared to the titanium rod construct, but constrained the anterior reconstruction in flexion and lateral bending, and extension under preload. The anterior graft shared higher load under a preload, particularly with the PEEK rod construct. The results of this study suggest that rigidity of rods in the anterior reconstruction affected kinematic behavior and load sharing.

\section{References:}

Abode-Iyamah, K., Kim, S.B., Grosland, N., Kumar, R., Belirgen, M., Lim, T.H., et al., 2014. Spinal motion and intradiscal pressure measurements before and after lumbar spine instrumentation with titanium or PEEK rods. J. Clin Neurosci. 21, 651-655.

Ahn, Y., Chen, W., Lee, K., Park, K., Lee, S., 2008. Comparison of the load-sharing characteristics between pedicle-based dynamic and rigid rod devices. Biomed. Mater. 3, 44101.

Brodke, D.S., Gollogly, S., Alexander, M.R., Nguyen, B.K., Dailey, A.T., Bachus, A., 2001. Dynamic cervical plates: biomechanical evaluation of load sharing and stiffness. Spine. 26, 1324-1329 (Phila $\mathrm{Pa}$ 1976).

Brodke, D.S., Gollogly, S., Bachus, K.N., Alexander, M.R., Nguyen, B.K., 2003. Anterior thoracolumbar instrumentation: stiffness and load sharing characteristics of plate and rod systems. Spine. 28, 1794-1801 (Phila Pa 1976).

Brodke, D.S., Klimo, P.J., Bachus, K.N., Braun, J.T., Dailey, A.T., 2006. Anterior cervical fixation: analysis of load-sharing and stability with use of static and dynamic plates. J. Bone Joint Surg. Am. $88,1566-1573$.

Chang, U.K., Lim, J., Kim, D.H., 2006. Biomechanical study of thoracolumbar junction fixation devices with different diameter dual-rod systems. J. Neurosurg Spine 4, 206-212.

De Iure, F., Bosco, G., Cappuccio, M., Paderni, S., Amendola, L., 2012. Posterior lumbar fusion by peek rods in degenerative spine: preliminary report on 30 cases. Eur. Spine J. 21, 50-54.

Dvorak, M.F., Pitzen, T., Zhu, Q., Gordon, J.D., Fisher, C.G., Oxland, T.R., 2005. Anterior cervical plate fixation: a biomechanical study to evaluate the effects of plate design, endplate preparation, and bone mineral density. Spine. 30, 294-301 (Phila Pa 1976).

Dvorak, M.F., Sekeramayi, F., Zhu, Q., Hoekema, J., Fisher, C., Boyd, M., et al., 2003. Anterior occiput to axis screw fixation: part II: a biomechanical comparison with posterior fixation techniques. Spine. 28, 239-245 (Phila Pa 1976).

Feighan, J.E., Stevenson, S., Emery, S.E., 1995. Biologic and biomechanic evaluation of posterior 
lumbar fusion in the rabbit. The effect of fixation rigidity. Spine. 20, 1561-1567(Phila Pa 1976).

Ferguson, S.J., Visser, J.M., Polikeit, A., 2006. The long-term mechanical integrity of non-reinforced PEEK-OPTIMA polymer for demanding spinal applications: experimental and finite-element analysis. Eur. Spine J. 15, 149-156.

Fry, R.W., Alamin, T.F., Voronov, L.I., Fielding, L.C., Ghanayem, A.J., Parikh, A., et al.,2014 Compressive preload reduces segmental flexion instability after progressive destabilization of the lumbar spine. Spine. 39, E74-E81 (Phila Pa 1976).

Gornet, M.F., Chan, F.W., Coleman, J.C., Murrell, B., Nockels, R.P., Taylor, B.A., et al., 2011. Biomechanical assessment of a PEEK rod system for semi-rigid fixation of lumbar fusion constructs. J. Biomech Eng. 133, 81009.

Kokkinos, P.A., Zarkadis, I.K., Kletsas, D., Deligianni, D.D., 2009. Effects of physiological mechanical strains on the release of growth factors and the expression of differentiation marker genes in human osteoblasts growing on Ti-6Al-4V J. Biomed Mater. Res. A. 90, 387-395.

Kurtz, S.M., Devine, J.N., 2007. PEEK biomaterials in trauma, orthopedic, and spinal implants. Biomaterials. 28, 4845-4869.

Moon, S.M., Ingalhalikar, A., Highsmith, J.M., Vaccaro, A.R., 2009. Biomechanical rigidity of an all-polyetheretherketone anterior thoracolumbar spinal reconstruction construct: an in vitro corpectomy model. Spine J. 9, 330-335.

Niosi, C.A., Wilson, D.C., Zhu, Q., Keynan, O., Wilson, D.R., Oxland, T.R., 2008. The effect of dynamic posterior stabilization on facet joint contact forces: an in vitro investigation. Spine. 33, 19-26 (Phila Pa 1976).

Niosi, C.A., Zhu, Q.A., Wilson, D.C., Keynan, O., Wilson, D.R., Oxland, T.R., 2006. Biomechanical characterization of the three-dimensional kinematic behaviour of the Dynesys dynamic stabilization system: an in vitro study. Eur. Spine J. 15, 913-922.

Ormond, D.R., Albert, L., Das, K., 2015. Polyetheretherketone (PEEK) Rods in Lumbar Spine Degenerative Disease. Journal of Spinal Disorders and Techniques.1.

Patel, M.J., Chang, K.H., Sykes, M.C., Talish, R., Rubin, C., Jo, H., 2009. Low magnitude and high frequency mechanical loading prevents decreased bone formation responses of $2 \mathrm{~T} 3$ preosteoblasts. J. Cell Biochem. 106, 306-316.

Patwardhan, A.G., Havey, R.M., Meade, K.P., Lee, B., Dunlap, B., 1999. A follower load increases the load-carrying capacity of the lumbar spine in compression. Spine. 24, 1003-1009 (Phila Pa 1976).

Ponnappan, R.K., Serhan, H., Zarda, B., Patel, R., Albert, T., Vaccaro, A.R., 2009. Biomechanical evaluation and comparison of polyetheretherketone rod system to traditional titanium rod fixation. Spine. J. 9, 263-267.

Qi, L., Li, M., Zhang, S., Xue, J., Si, H., 2013. Comparative effectiveness of PEEK rods versus titanium alloy rods in lumbar fusion: A preliminary report. Acta. Neurochir. 155, 1187-1193.

Reidy, D., Finkelstein, J., Nagpurkar, A., Mousavi, P., Whyne, C., 2004. Cervical spine loading characteristics in a cadaveric C5 corpectomy model using a static and dynamic plate. J. Spinal Disord. Tech. 17, 117-122.

Rivard, C.H., Rhalmi, S., Coillard, C., 2002. In vivo biocompatibility testing of peek polymer for a spinal implant system: a study in rabbits. J. Biomed Mater. Res. 62, 488-498.

Sengupta, D.K., Bucklen, B., McAfee, P.C., Nichols, J., Angara, R., Khalil, S., 2013. The Comprehensive Biomechanics and Load-Sharing of Semirigid PEEK and Semirigid Posterior Dynamic Stabilization Systems. Advances. In Orthopedics. 2013, 1-9. 
Sjovold, S.G., Zhu, Q., Bowden, A., Larson, C.R., de Bakker, P.M., Villarraga, M.L., et al., 2012. Biomechanical evaluation of the Total Facet Arthroplasty System(R) (TFAS(R)): loading as compared to a rigid posterior instrumentation system. Eur. Spine J. 21, 1660-1673.

Turner, J.L., Paller, D.J., Murrell, C.B., 2010. The mechanical effect of commercially pure titanium and polyetheretherketone rods on spinal implants at the operative and adjacent levels. Spine. 35, E1076-E1082 (Phila Pa 1976).

Voronov, L.I., Vastardis, G., Zelenakova, J., Carandang, G., Havey, R.M., Waldorff, E.I., et al., 2014. Biomechanical characteristics of an integrated lumbar interbody fusion device. Int J. Spine Surg. 8.

Wilke, H.J., Wenger, K., Claes, L., 1998. Testing criteria for spinal implants: recommendations for the standardization of in vitro stability testing of spinal implants. Eur. Spine J. 7, 148-154.

Yu, A.K., Siegfried, C.M., Chew, B., Hobbs, J., Sabersky, A., Jho, D.J., et al., 2015. Biomechanics of Posterior Dynamic Fusion Systems in the Lumbar Spine. Journal of Spinal Disorders and Techniques. 1.

Zhu, Q., Itshayek, E., Jones, C.F., Schwab, T., Larson, C.R., Lenke, L.G., et al., 2012. Kinematic evaluation of one- and two-level Maverick lumbar total disc replacement caudal to a long thoracolumbar spinal fusion. Eur. Spine J. 21 Suppl 5, S599-S611.

Zhu, Q., Larson, C.R., Sjovold, S.G., Rosler, D.M., Keynan, O., Wilson, D.R., et al., 2007. Biomechanical evaluation of the Total Facet Arthroplasty System: 3-dimensional kinematics. Spine. 32, 55-62 (Phila Pa 1976).

\section{Figure legends}

Figure 1. A T11-L3 spine specimen from the present study in the custom spine machine. The specimen in shown in the flexion-extension configuration. The pure moment $5 \mathrm{Nm}$ was applied to the specimen through a loading arm which consisted of a servo-motor, gear, two U-joints, a linear bearing and a torque load cell. The loading arm position is shifted to obtain the three spinal motions (flexion-extension, lateral bending and axial rotation). A follower preload of $300 \mathrm{~N}$ was applied with bilateral cables (arrows) which were anchored at T11 and through the eyelets at L3, and dead weight underneath. The segmental motion was monitored using a marker carrier with 4 infrared emitting diodes (Optotrak; Northern Ditital, Ontario).

Figure 2.Anteroposterior and lateral pictures of L1 reconstruction with titanium and PEEK rods. A surrogate bone graft embedded with a load cell of compressive force was used in the reconstruction of L1 corpectomy.

Figure 3. A typical schematic of compressive force of the surrogate bone graft in the anterior reconstruction of L1 corpectomy during the flexibility test in flexion-extension with and without a follower preload. A pure moment of $5 \mathrm{Nm}$ was applied to the specimen from extension to flexion in three cycles. The bone graft was compressed during the instrumentation with PEEK and titanium rods, respectively. 
Figure 4. Average T12-L2 ROMs of the intact and constructs with titanium and PEEK rods. The ROM represented rotation angle in flexion, extension, unilateral lateral bending and unilateral axial rotation under pure moment of $5 \mathrm{Nm}$ with and without a compressive preload of $300 \mathrm{~N}$. Vertical bars denote 0.95 confidence intervals. Significant differences exist when compared with the intact $\left(^{*}\right)$, the titanium rod construct $\left(^{\#}\right)$ and the intact without preload $\left({ }^{\&}\right)(\mathrm{p}<0.05)$.

Figure 5. Changes of the compressive force in the anterior graft of the L1 corpectomy reconstruction with titanium and PEEK rods during flexibility test in flexion and extension, respectively. The force changes are represented at maximal flexion and maximal extension with and without a compressive follower preload of $300 \mathrm{~N}$ and pure moment of $5 \mathrm{Nm}$. Vertical bars denote 0.95 confidence intervals. 
Figure 1

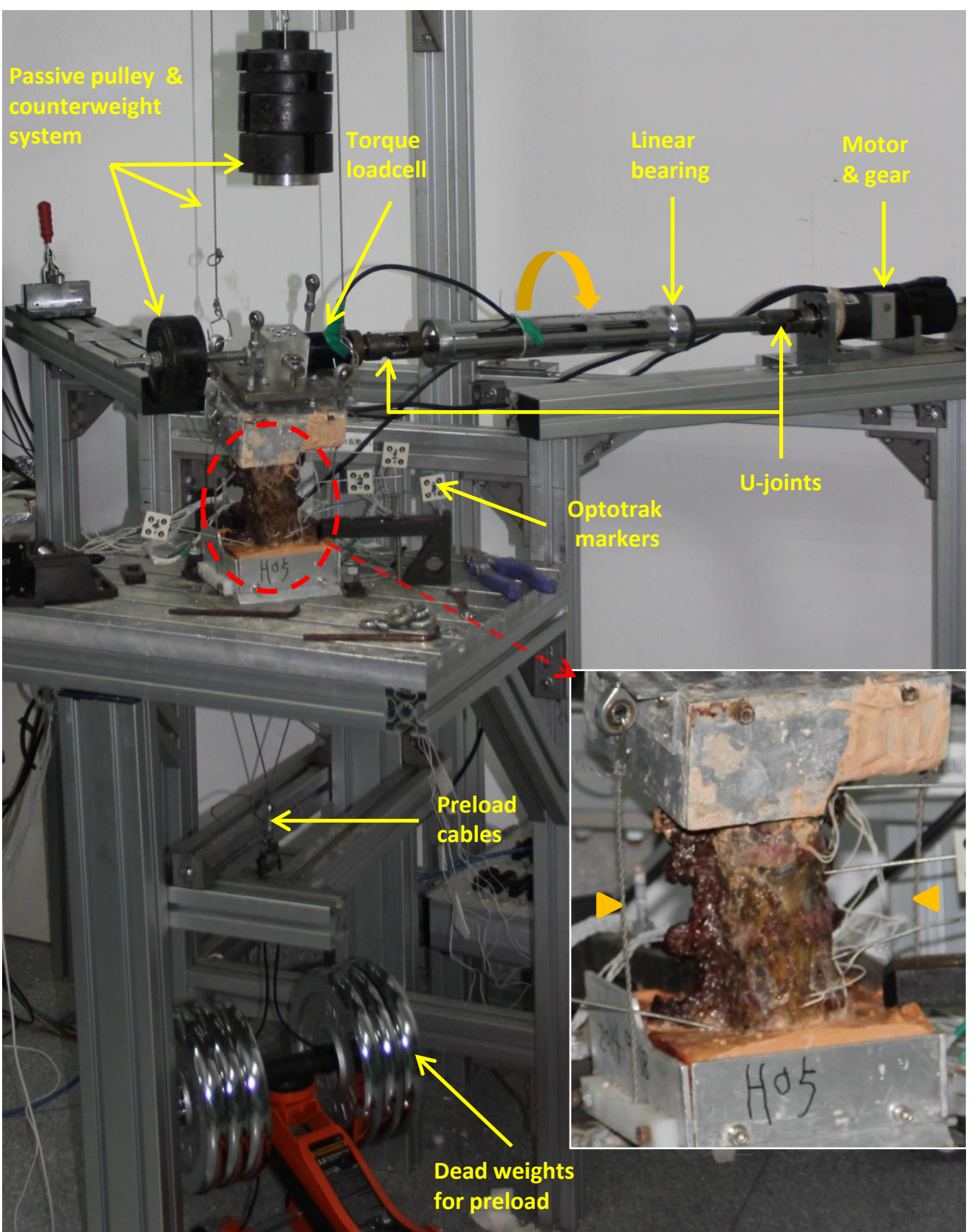


Figure 2

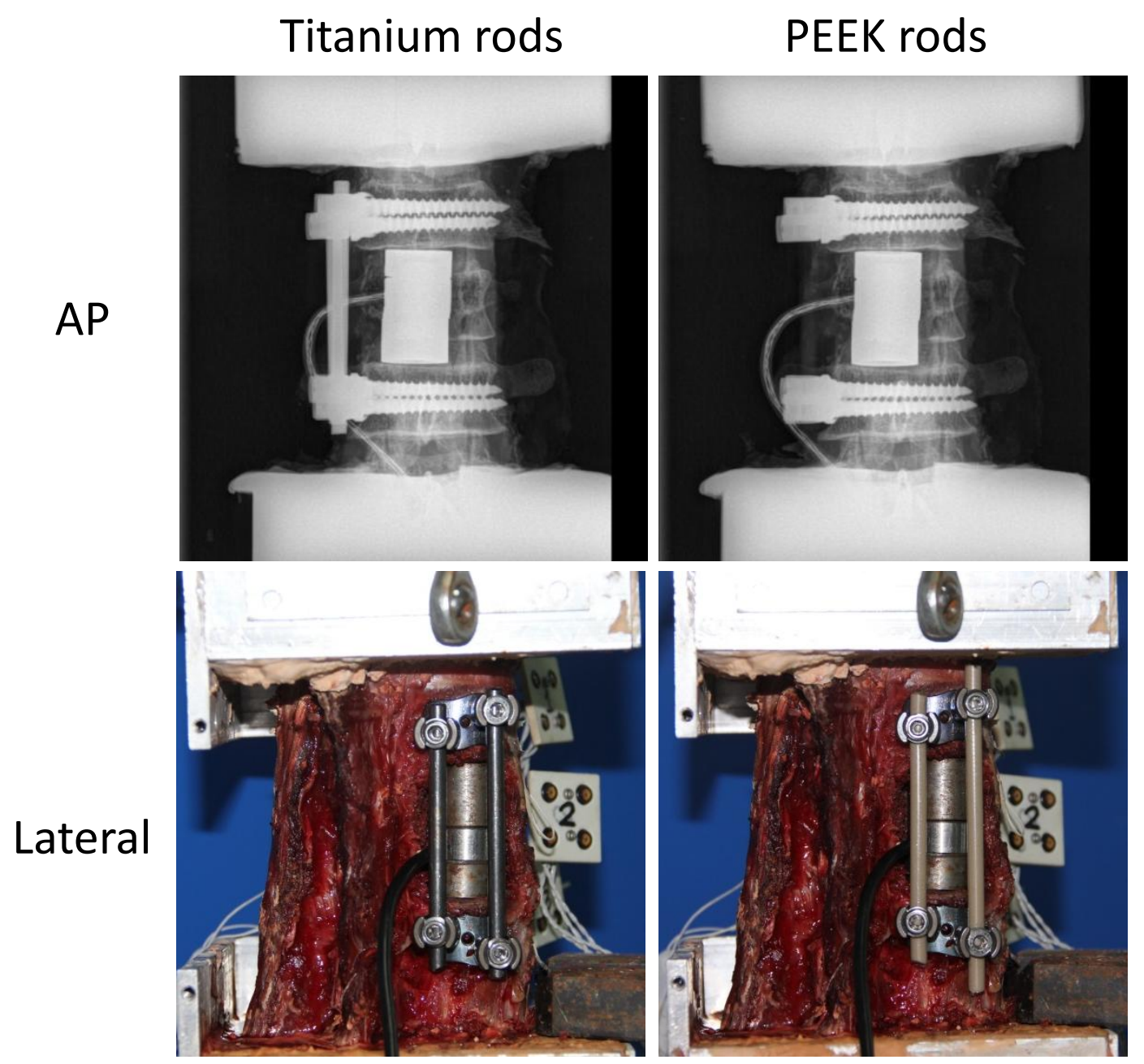


Figure 3

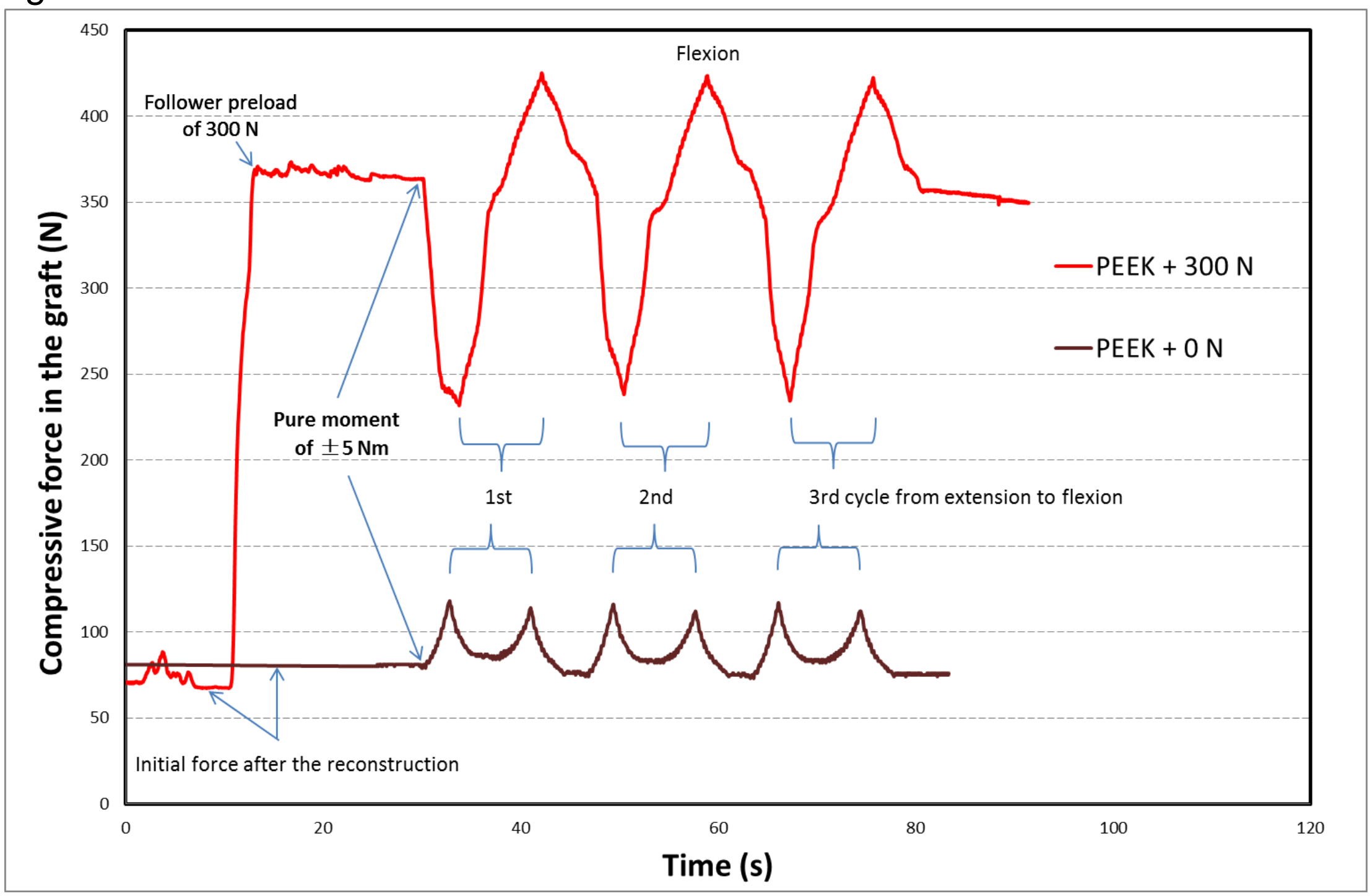


Figure 4

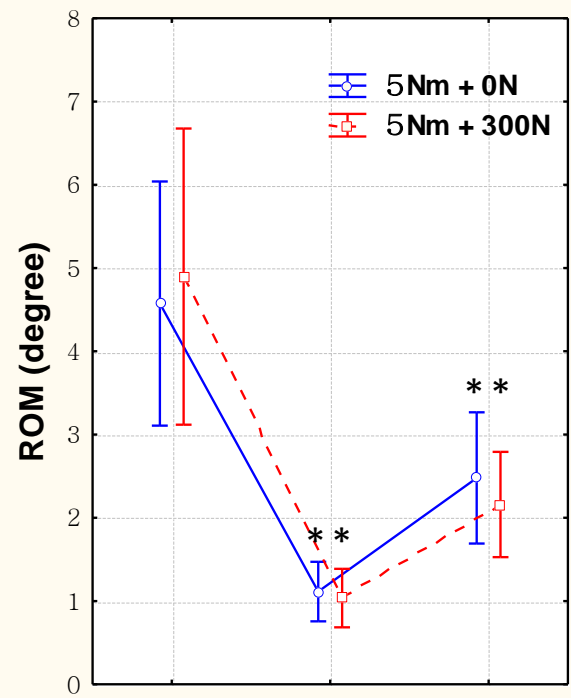

Intact Titanium PEEK

\section{Flexion}

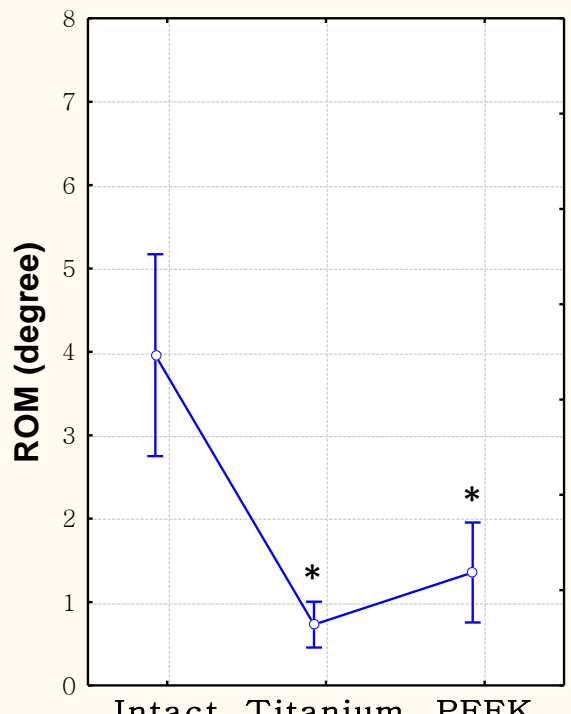

Intact Titanium PEEK

Lateral bending

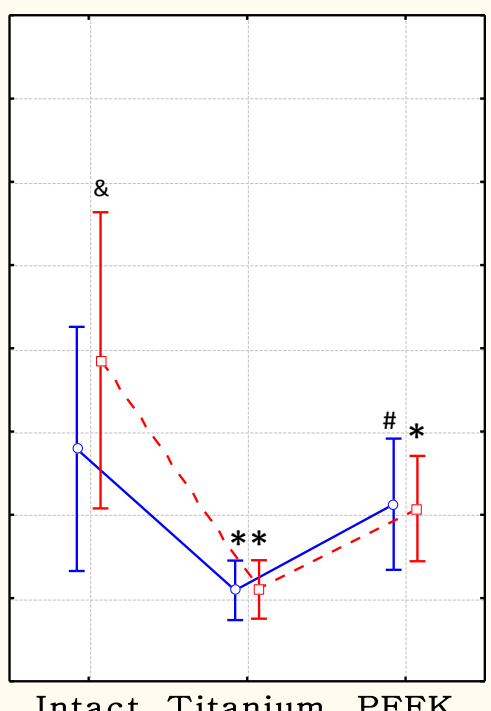

Extension

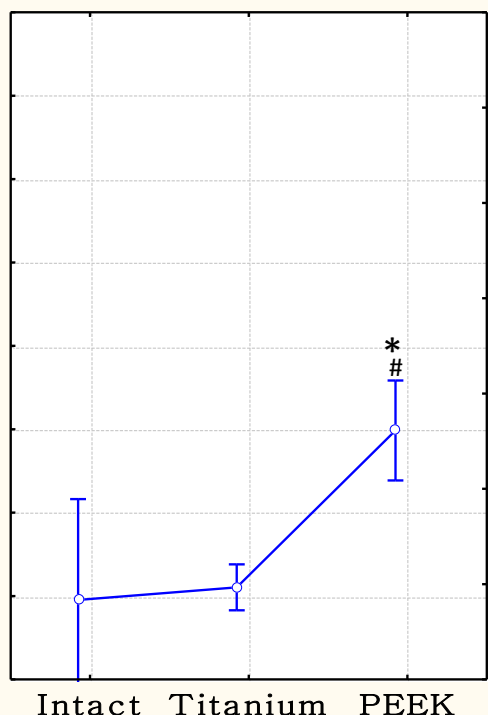

Axial rotation 
Figure 5
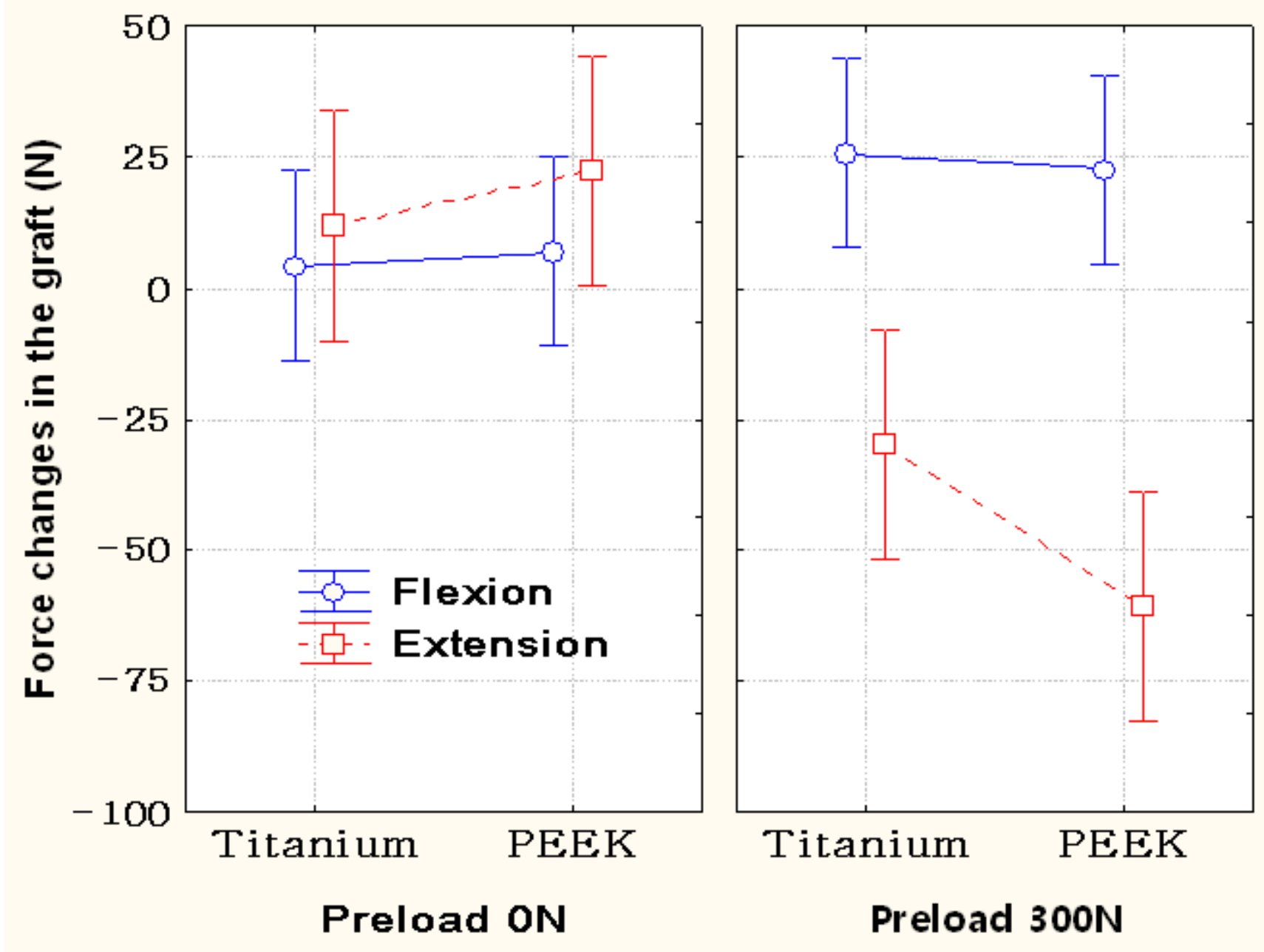
Table 1. Average neutral zone (NZ) of the intact specimen and two constructs with titanium and PEEK rods in flexion-extension, lateral bending and axial rotation.

\begin{tabular}{lllll}
\hline Condition & Flexion-extension & $\begin{array}{l}\text { Lateral } \\
\text { bending }\end{array}$ & $\begin{array}{l}\text { Axial } \\
\text { rotation }\end{array}$ & $\begin{array}{l}\text { Flexion-extension } \\
\text { with a preload }\end{array}$ \\
\hline Intact & $0.3(0.1)$ & $0.4(0.5)$ & $0.1(0.0)$ & $0.8^{*}(0.5)$ \\
Titanium rods & $0.3(0.2)$ & $0.1^{\#}(0.1)$ & $0.2^{\#}(0.1)$ & $0.3^{\#}(0.2)$ \\
PEEK rods & $0.4(0.3)$ & $0.2(0.1)$ & $0.3^{\#}(0.1)$ & $0.4(0.2)$ \\
\hline
\end{tabular}

All values are Newton. Data are mean (standard deviation). Titanium and PEEK rods represent the anterior reconstruction of L1 corpectomy with titanium and PEEK rods, respectively. Significant difference from the intact $\left(^{\#}\right)$ and the intact without a preload $(*)(\mathrm{p}<0.05)$. 
Table 2: Absolute compressive forces for the anterior reconstruction graft stabilized with titanium and PEEK rod constructs.

\begin{tabular}{|c|c|c|c|c|}
\hline Condition & Installation & $\begin{array}{l}\text { Neutral } \\
\text { position }\end{array}$ & Flexion & Extension \\
\hline $\begin{array}{l}\text { Titanium rods } \\
+0 \mathrm{~N}\end{array}$ & $63(30)$ & $63(30)$ & $75(32)$ & $68(31)$ \\
\hline $\begin{array}{l}\text { PEEK rods } \\
+0 \mathrm{~N}\end{array}$ & $52(23)$ & $52(23)$ & $74(46)$ & $59(49)$ \\
\hline $\begin{array}{l}\text { Titanium rods } \\
+300 \mathrm{~N}\end{array}$ & $58(28)$ & $123(51)$ & $149(58)$ & $89(39)$ \\
\hline $\begin{array}{l}\text { PEEK rods } \\
+300 \mathrm{~N}\end{array}$ & $60(24)$ & $203^{\#}(74)$ & $230^{\#}(89)$ & $136^{\#}(64)$ \\
\hline \multicolumn{5}{|c|}{$\begin{array}{l}\text { All values are Newton. Data are mean (standard deviation). Titanium and PEEK rods } \\
\text { represent the anterior reconstruction of L1 corpectomy with titanium and PEEK rods, } \\
\text { respectively. " significant difference from the titanium rod construct with preload } \\
(\mathrm{p}<0.05)\end{array}$} \\
\hline
\end{tabular}

